\title{
O CIRCUITO ESPACIAL PRODUTIVO DE CELULOSE EM SELVÍRIA, MATO GROSSO DO SUL
}

\author{
Leandro Reginaldo Maximino Lelis \\ Doutorando no Programa de Pós-Graduação e Pesquisa em Geografia \\ Universidade Federal do Rio Grande do Norte \\ sukk051@hotmail.com \\ Celso Donizete Locatel \\ Professor do Programa de Pós-Graduação e Pesquisa em Geografia \\ Universidade Federal do Rio Grande do Norte \\ celso.locatel@gmail.com \\ Cesar Cardoso Ferreira \\ Professor Colaborador no Programa de Pós-Graduação em Geografia \\ Universidade Federal de Mato Grosso do Sul \\ cesar.ufms@gmail.com \\ Heloissa Gabriela Silva Sokolowski \\ Mestre pelo Programa de Pós-Graduação em Geografia \\ Universidade Federal de Mato Grosso do Sul \\ geo.sokolowski@gmail.com
}

\begin{abstract}
RESUMO
Este artigo tem como objetivo analisar os principais impactos gerados pela expansão do circuito espacial produtivo de celulose em Selvíria. A partir dos procedimentos metodológicos realizados, constatou-se que o circuito espacial produtivo de celulose causa efeitos na cidade e no campo. $\mathrm{Na}$ cidade, as consequências estão ligadas, principalmente, à movimentação de trabalhadores nos hotéis e restaurantes, à alteração na estrutura ocupacional da mão de obra e à circulação de ônibus e caminhões de empresas ligadas ao circuito analisado. Entretanto, as principais repercussões ocorrem no campo, especialmente nos assentamentos da reforma agrária. Se por um lado os assentados são beneficiados pelas ações compensatórias realizadas pelas companhias fabricantes de celulose, por outro sofrem diversos impactos, como a deterioração das estradas rurais, a poeira gerada pelo tráfego intenso de veículos, a invasão de pragas, a contaminação das lavouras por agrotóxicos aplicados nos eucaliptais e a redução dos cursos d'água.
\end{abstract}

Palavras-chave: Circuito espacial produtivo. Celulose. Selvíria.

\section{THE PRODUCTIVE SPACE CIRCUIT OF CELLULOSE IN SELVÍRIA, MATO GROSSO DO SUL}

\begin{abstract}
This article has as objective analysis the main impacts produced by the from the methodological processes done it was noticed that the productive space cellulose circuit causes effects in the city and in the field. In the city, the consequences are tied, mainly to the workers' movement in the hotels and restaurants to the alteration in the occupational structure of the labor and to the circulation of bus and lorries of enterprises connected with the analysed circuit. Meantime, the main repercussions take place in the field, specially in the registrations of the land reform. If on a side established cellulose manufacturers are benefited by the compensatory actions carried out by the companies, for other they suffer several impacts, like the deterioration of the rural roads, the dust produced by the intense traffic of vehicles, the invasion of nuisances, the contamination of the lavouras for pesticides when in were applied eucaliptais and the reduction of the wattercourses.
\end{abstract}

Keywords: Productive space circuit. Cellulose. Selvíria.

\section{INTRODUÇÃO}

O circuito espacial produtivo de celulose (CEPC) expandiu-se no município de Selvíria, extremo Leste de Mato Grosso do Sul, em meados da década de 2000, a partir do anúncio da instalação da primeira

\begin{tabular}{llllll}
\hline Caminhos de Geografia & Uberlândia & v. 21, n. 73 & Mar/2020 & p. 269-283 & Página 269
\end{tabular}


fábrica de celulose no estado, localizada no município vizinho de Três Lagoas. Com capacidade para produzir 1,3 milhões de toneladas de celulose por ano, o "Projeto Horizonte", anunciado em 2006 e concluído em 2009, foi realizado pela Votorantim Celulose e Papel (VCP) em parceria com a International Paper (IP). No ano da inauguração, a VCP se uniu a Aracruz Celulose formando a Fibria Celulose S/A (KUDLAVICZ, 2011; PERPETUA, 2012).

Em 2010, anunciou-se a instalação de mais uma unidade fabril produtora de celulose, a Eldorado Brasil, também localizada em Três Lagoas, mas desta vez mais próxima ao município de Selvíria. A empresa foi fundada em 15 de junho de 2010 por meio de uma parceria entre a J\&F Participações e a MCL Participações. Sua linha de produção foi inaugurada em 2012, possuindo capacidade para produzir 1,7 milhão de tonelada por ano.

No ano de 2012, a Fibria anunciou a expansão de sua unidade fabril no município de Três Lagoas, concluída em 2017. O "Projeto Horizonte 2" possui capacidade produtiva de 1,75 milhão de toneladas anuais. Assim, as duas linhas da Fibria em Três Lagoas possuem capacidade para produzir 3,05 milhões de toneladas por ano. No total, a Fibria e a Eldorado Brasil possuem capacidade para produzir 4,75 milhões de toneladas anuais de celulose, tornando Três Lagoas o maior município produtor de celulose do mundo.

Em decorrência da grandiosidade dos projetos de celulose, uma base territorial precisou ser formada para abastecer as fábricas. Deste modo, os monocultivos florestais não ficaram restritos a Três Lagoas, sede das agroindústrias de celulose, pelo contrário, expandiram-se em vários municípios de Mato Grosso do Sul, sobretudo de sua região Leste, como é o caso de Selvíria.

Devido à proximidade em relação a Três Lagoas, Selvíria tem se configurado como um dos municípios sul-mato-grossenses mais inseridos no circuito espacial produtivo de celulose, situação evidenciada pela expansão dos monocultivos florestais. Nesse contexto, este artigo objetiva analisar os principais impactos gerados pela expansão do circuito espacial produtivo de celulose em Selvíria.

Para a consecução do objetivo proposto foram realizados os seguintes procedimentos metodológicos: leitura e análise do material bibliográfico selecionado; coleta e análise de dados de fontes secundárias; elaboração de mapas; relização de trabalho de campo.

A leitura e análise bilbiográfica foi pautada em produções teóricas que abordam a noção de circuitos espaciais de produção, base teórica desta pesquisa. Para isso, alguns trabalhos foram utilizados, com destaque para Moraes (1985), Santos (1997), Santos e Silveira (2014), Marx (2011) e Castillo e Frederico (2010). Além disso, também foram utilizados trabalhos que analisaram a produção de eucalipto e de celulose, bem como seus desdobramentos no Leste de Mato Grosso do Sul, como Almeida (2010), Kudlavicz (2011) e Perpetua (2012; 2016).

A coleta e análise de dados de fontes secundárias ocorreu com o intuito de identificar algumas modificações ocorridas em Selvíria nos últimos anos devido à expansão do CEPC. Nesse sentido, foram visitados os sítios eletrônicos do Ministério do Trabalho e Emprego (MTE), para a obtenção de dados referentes à ocupação da mão de obra, e do Instituto Brasileiro de Geografia e Estatística (IBGE), para a coleta de dados relativos ao efetivo bovino e à dinâmica populacional.

Os mapas foram produzidos objetivando apresentar a localização dos municípios de Selvíria e de Três Lagoas, das fábricas produtoras de celulose (Fibria e Eldorado Brasil) e dos assentamentos da reforma agrária estudados. Com o intuito de evidenciar espacialmente a expansão dos monocultivos de eucalipto, também foram elaborados dois mapas de uso e cobertura da terra do município de Selvíria, referentes aos anos de 2000 e 2018. O ano de 2000 foi selecionado por representar o início da década de instalação da primeira fábrica de celulose em Mato Grosso do Sul, enquanto 2018 foi escolhido em função de ser o ano do trabalho de campo realizado no município pesquisado.

Os mapas de uso e cobertura da terra tiveram como base imagens orbitais oriundas dos Satélites Landsat 7 sensor Thematic Mapper, bandas 4, 5 e 6, no ano de 2000 e Landsat 8 sensor Operational Land Imager, bandas 4, 5 e 6, no ano de 2018. Além disso, tais dados orbitais foram interpretados, classificados e validados por meio de procedimentos operacionais realizados em um ambiente de sistemas destinados à aquisição, armazenamento, manipulação, análise e apresentação de dados georreferenciados, ou seja, um Sistema de Informação Geográfica (SIG).

O trabalho de campo teve como objetivo identificar e analisar alguns reflexos gerados pelo circuito especial produtivo de celulose em Selvíria. Para isso, na cidade foram visitados estabelecimentos comerciais para averiguar possíveis alterações ocorridas após a expansão do circuito pesquisado a

$\begin{array}{lllll}\text { Caminhos de Geografia } & \text { Uberlândia } & \text { v. 21, n. } 73 & \text { Mar/2020 } & \text { p. 269-283 Página } 270\end{array}$


partir de conversas com seus respectivos proprietários. Além disso, também foram realizados diálogos com trabalhadores ligados ao CEPC que se encontravam na cidade, principalmente nos hotéis e restaurantes visitados. No campo, foram pesquisados três assentamentos da reforma agrária, a saber: Alecrim, Canoas e São Joaquim. Estes foram selecionados com o intuito de conhecer possíveis rebatimentos ocasionados pela expansão do circuito em questão aos sujeitos sociais do campo, os quais possivelmente estão entre os mais afetados pelas atividades ligadas à produção florestal e de celulose.

Além do resumo, desta introdução, das considerações finais e das referências, mais três itens compõem este artigo. O primeiro apresenta breve reflexão acerca dos circuitos espaciais produtivos, noção utilizada para o embasamento teórico desta pesquisa. $O$ segundo expõe a expansão dos eucaliptais em Selvíria, principal evidência da ampliação da inserção do município no circuito espacial produtivo de celulose. Por fim, o terceiro evidencia os principais efeitos da inserção em questão, como as alterações na dinâmica do comércio local, na estrutura ocupacional da mão de obra, nas relações de trabalho e, principalmente, os impactos gerados no campo, sobretudo nos assentamentos da reforma agrária.

\section{A NOÇÃO DE CIRCUITO ESPACIAL PRODUTIVO}

Santos e Silveira (2014) apontam que o mundo atual é caracterizado pela ampliação da segmentação das etapas de trabalho e pela consequente intensificação das relações e trocas entre as diferentes regiões. Estas relações não ocorrem apenas entre regiões próximas, pois em função do desenvolvimento atual dos meios de transportes e de telecomunicações, as relações ocorrem entre regiões cada vez mais distantes. Uma área de agricultura moderna, por exemplo, pode ter relações mais frequentes com cidades distantes, às vezes até em outros países, do que com as cidades mais próximas. Destarte, os autores afirmam que essas características evidenciam a noção de circuito espacial produtivo.

Segundo Castillo e Frederico (2010, p. 463, grifo dos autores):

A noção de circuito espacial produtivo enfatiza, a um só tempo, a centralidade da circulação (circuito) no encadeamento das diversas etapas da produção; a condição do espaço (espacial) como variável ativa na reprodução social; e o enfoque centrado no ramo, ou seja, na atividade produtiva dominante (produtivo).

Essa denominação tinha como propósito superar a ideia de circuitos regionais produtivos, por entender que os circuitos de produção, no atual período, possuem fluxos, materiais e imateriais, dotados de diferentes intensidades, vindos de todas as direções, extrapolando a escala regional (SANTOS, 1997). Nesse sentido, Moraes (1985, p. 3) pontua que os circuitos espaciais de produção devem ser "[...] discutidos na ótica da mundialização do espaço geográfico e da globalização das relações sociais de produção". Partindo deste pressuposto, é impossível considerar que um circuito espacial de produção se restrinja a escala regional.

No caso do circuito especial produtivo de celulose em Mato Grosso do Sul, por exemplo, foi possível notar uma multiescalaridade geográfica, interligando o lugar ao global, pois a celulose é produzida no estado a partir de tecnologias de empresas sediadas em países do Norte. Após a produção, mais de $80 \%$ da celulose produzida em MS é exportada, principalmente para os países do Norte e para a China. Esse contexto demonstra que a celulose é produzida em Mato Grosso do Sul, mais precisamente em Três Lagoas, a partir de uma lógica global, evidenciada tanto a montante como a jusante do processo produtivo da celulose.

Importante mencionar que essa conjutura ocorre devido à nova divisão territorial do trabalho no circuito espacial produtivo de papel, que ocorre na escala global e na nacional. Na escala global, essa nova divisão é caracterizada pela transferência das etapas iniciais do circuito espacial produtivo de papel - produção florestal e de celulose - dos países do Norte para os do Sul. Na escala nacional, a nova divisão territorial é marcada pela interiorização dessas etapas iniciais, resultando na ampliação da produção florestal e de celulose em estados pouco tradicionais nesses setores, como é o caso de Mato Grosso do Sul. Destarte, a nova divisão territorial do trabalho possibilitou a dispersão das etapas iniciais do circuito espacial produtivo de papel pelo mundo, ampliando as relações entre lugares longínquos, mas inter-relacionados por uma lógica econômica global.

$\begin{array}{lllll}\text { Caminhos de Geografia } \quad \text { Uberlândia } & \text { v. 21, n. 73 } & \text { Mar/2020 } & \text { p. 269-283 Página } 271\end{array}$


Para Santos e Silveira (2014, p. 143), a abordagem por meio dos circuitos espaciais de produção é fundamental para a compreensão do território em movimento, pois como os circuitos espaciais referem-se à circulação de bens e produtos, possibilitam "[...] uma visão dinâmica, apontando a maneira como os fluxos perpassam o território". Nessa perspectiva, a partir da noção em questão, foi possível captar como frações significativas do território sul-mato-grossense são utilizadas corporativamente a partir das verticalidades do mercado global, as quais impõem novas dinâmicas ao Leste sul-mato-grossense, alterando as lógicas locais e regional. Esse contexto revela como as dinâmicas dos lugares têm sido alteradas para atender aos interesses do capital, nesse caso representado pelas empresas integrantes do CEPC.

De acordo com Santos (1997, p. 49), o circuito espacial de produção refere-se às "[...] diversas etapas pelas quais passaria um produto, desde o começo do processo de produção até chegar ao consumo final". Assim, para compreender o circuito espacial produtivo de celulose, tem de se analisar todos os momentos da produção - a produção propriamente dita, a distribuição, a troca (circulação) e o consumo (MARX, 2011). Dessa maneira, para a compreensão do CEPC em Mato Grosso do Sul, foi necessário entender desde as ações iniciais ligadas às pesquisas, passando pelo viveiro de mudas, pela produção florestal, pela produçao industrial de celulose, até chegar ao destino final da celulose. Tal situação notabiliza a necessidade de também entender as lógicas que permeiam os circuitos espaciais produtivos que o complementam. Foi a partir desse princípio que se conseguiu compreender a multiescalaridade geográfica do circuito pesquisado.

A noção de circuito espacial produtivo deve ser acompanhada da noção de círculos de cooperação no espaço. Estes são definidos pelos agentes dos circuitos espaciais produtivos, pois, ao possibilitarem a articulação entre os diferentes agentes, etapas e lugares contribuem para o desenvolvimento do circuito. Por isso, os circuitos espaciais produtivos necessitam dos círculos de cooperação no espaço.

Para Moraes (1985, p. 25), os círculos de cooperação no espaço "[...] integram diferentes lugares numa mesma circularidade (de mercadorias e de capitais). Estes círculos desenham hierarquias, especializações, fluxos. Suas sobreposições delineiam a divisão territorial do trabalho".

Segundo Castillo e Frederico (2010), os circuitos espaciais de produção estão relacionados aos fluxos materiais (mercadorias), enquanto os círculos de cooperação no espaço referem-se aos fluxos imateriais (capitais, ordens, informações). Nesse sentido, Castillo e Frederico (2010, p. 464) apontam que os círculos de cooperação devem ser "[...] entendidos como a relação estabelecida entre lugares e agentes por intermédio dos fluxos de informação". Ainda conforme os autores: "os círculos de cooperação são essenciais por permitirem colocar em conexão as diversas etapas especialmente separadas, da produção, articulando os diversos agentes e lugares que compõem o circuito espacial da produção" (CASTILLO; FREDERICO, 2010, p. 464).

Os círculos de cooperação no espaço, por exemplo, possibilitam que uma empresa sediada em determinada cidade possua suas unidades de produção em outros estados e até em outros países. Por meio de seus círculos de cooperação, esta empresa controlará suas unidades produtivas mesmo que estas estejam a centenas ou milhares de quilômetros. Assim, conforme Moraes (1985), em virtude dos círculos de cooperação no espaço, a produção pode se diversificar, mas a decisão permanece centralizada.

Os círculos de cooperação do CEPC são constituídos pelas companhias fabricantes de celulose, aliadas ao Estado (nas instâncias federal, estadual e municipal), às instituições financeiras, universidades, instituições de pesquisa, associações setoriais, organizações normativas e instituições formadoras e qualificadoras de mão de obra. Esses agentes que compõem os círculos de cooperação formam um sistema extremamente articulado em diversos níveis (econômico, político, normativo, científico) e escalas (desde a global até a local), aspecto fundamental para a estruturação e a expansão do circuito pesquisado em Mato Grosso do Sul. Este sistema é marcado por fluxos materiais e imateriais de diversas ordens, conteúdos e intensidades, interligando os agentes integrantes dos círculos de cooperação do circuito espacial produtivo de celulose, além de proporcionar a articulação entre as etapas produtivas e os lugares separados espacialmente.

Conforme Santos e Silveira (2014), no contexto atual, marcado pelo processo de globalização, pela internacionalização do capital, pela difusão de técnicas cada vez mais modernas, pela crescente

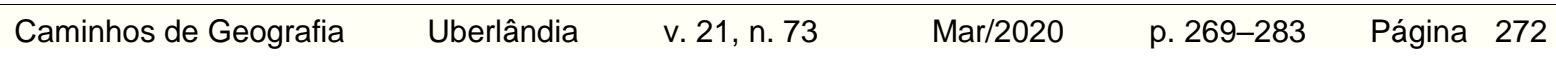


especialização produtiva regional, pela ampliação dos fluxos materiais e imateriais, dentre outros aspectos, a noção dos circuitos espaciais produtivos, acompanhada dos círculos de cooperação no espaço, é fundamental para a compreensão da organização, da regulação e do uso dos territórios.

Entende-se que a partir da noção apresentada será possível compreender e analisar a inserção do município de Selvíria no circuito espacial produtivo de celulose, ocorrida em função da expansão de monocultivos de eucalipto, matéria-prima para a produção de celulose. A expansão dos eucaliptais tem apresentado crescimento significativo nos últimos anos, ampliando, por consequência, a inserção de Selvíria no circuito estudado, conforme será explanado no próximo item.

\section{A EXPANSÃO DO CIRCUITO ESPACIAL PRODUTIVO DE CELULOSE EM SELVÍRIA}

O município de Selvíria (Mapa 1) possui pouco mais de 6.000 habitantes. Sua formação ocorreu devido à construção da hidrelétrica de Ilha Solteira, realizada pela Companhia Energética de São Paulo (CESP), durante a década de 1960. No decorrer da década de 1970 as obras foram finalizadas, muitos trabalhadores migraram, porém outros permaneceram na vila, que foi elevada a distrito de Três Lagoas, em 1976, e a município, em 1980 (IBGE, 2019).

Mapa 1 - Localização de Selvíria, de Três Lagoas e das indústrias produtoras de celulose.

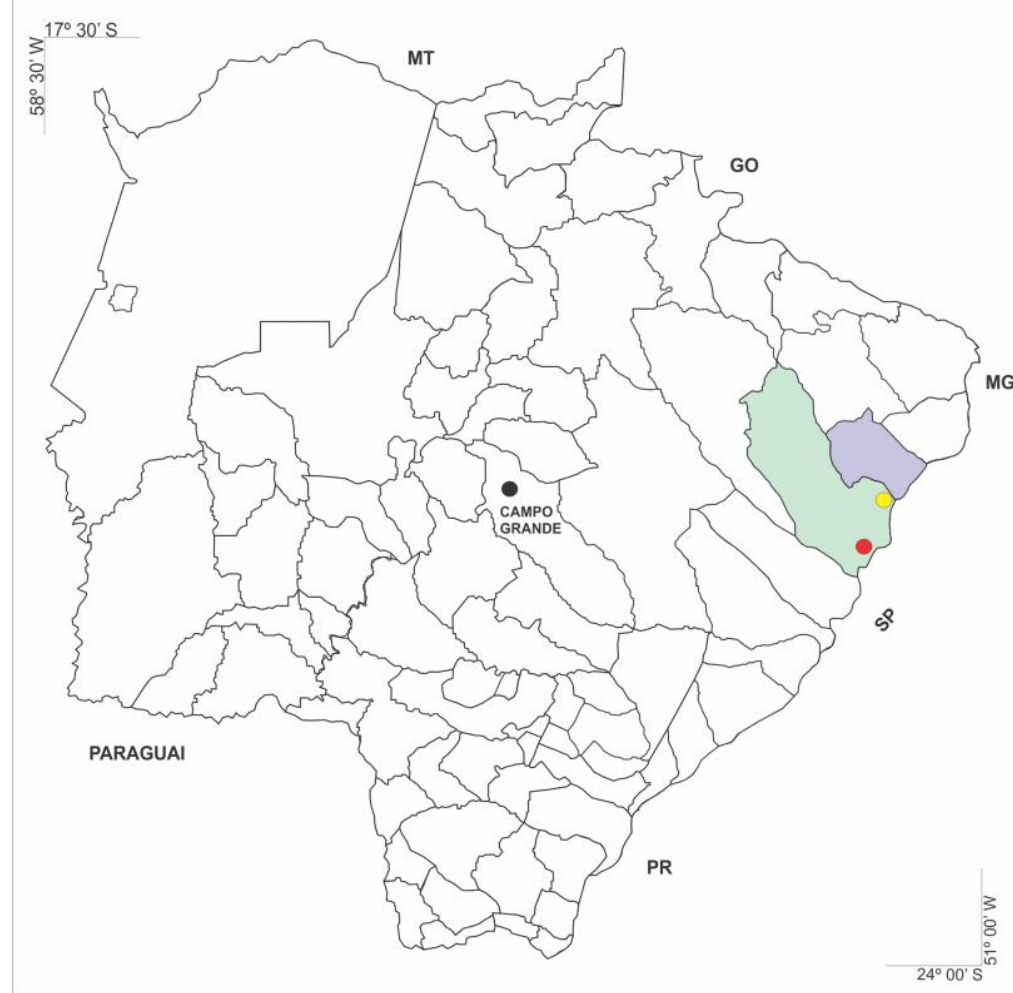

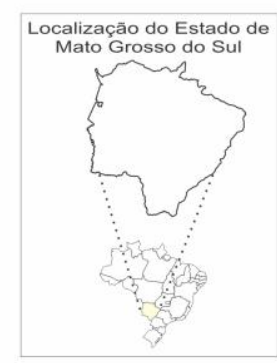

Legenda

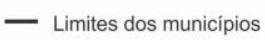

$\square$ Municipio de Três Lagoas

Municipio de Selviria

- Capital do Estado

- Fibria

Eldorado Brasil

Escala

$0 \quad 50 \quad 100 \quad 150 \mathrm{~km}$

60 UFRN - Universidade Federal do Rio Grande do Norte LABAGRARIUS - Laboratstrio de Estudos Rurais, Teconologia Sociale e hovers
UFMS - Universidade Federal de Mato Grosso do SuI UFMS - Universidade Federal de Mato Grosso do
LAPEGEO - Laboratorono de Praticas e Geoprocessamento LAPEGEO - Laboratónio de Pratica e Geoprcioss Cesar Cardoso Ferreira

Fonte - IBGE, 2018.

Antes da expansão do circuito espacial produtivo de celulose, Selvíria possuía uma estrutura agropecuária pouco dinâmica, baseada na criação de gado extensivo, atividade predominante no Leste sul-mato-grossense. Tal contexto favoreceu a expansão dos monocultivos florestais, que, em poucos anos, passaram a ocupar área significativa do município (ALMEIDA, 2010; KUDLAVICZ, 2011; PERPETUA, 2012).

Visando evidenciar o crescimento da área ocupada pelos eucaliptais, foram eleborados mapas de uso e ocupação da terra (mapa 2 e mapa 3), referentes aos anos de 2000 e 2018. No mapa 2 é possível notar que, em 2000, havia pequenas áreas ocupadas por eucalipto em Selvíria. Naquele momento, não existiam agroindústrias produtoras de celulose no estado, porém os eucaliptais serviam para abastecer as carvoarias e serrarias existentes na região (KUDLAVICZ, 2011).

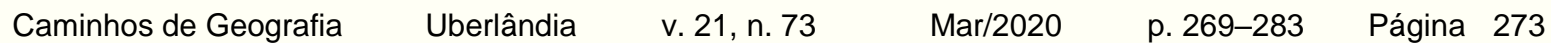


Mapa 2 - Selvíria: uso e cobertura da terra (2000).

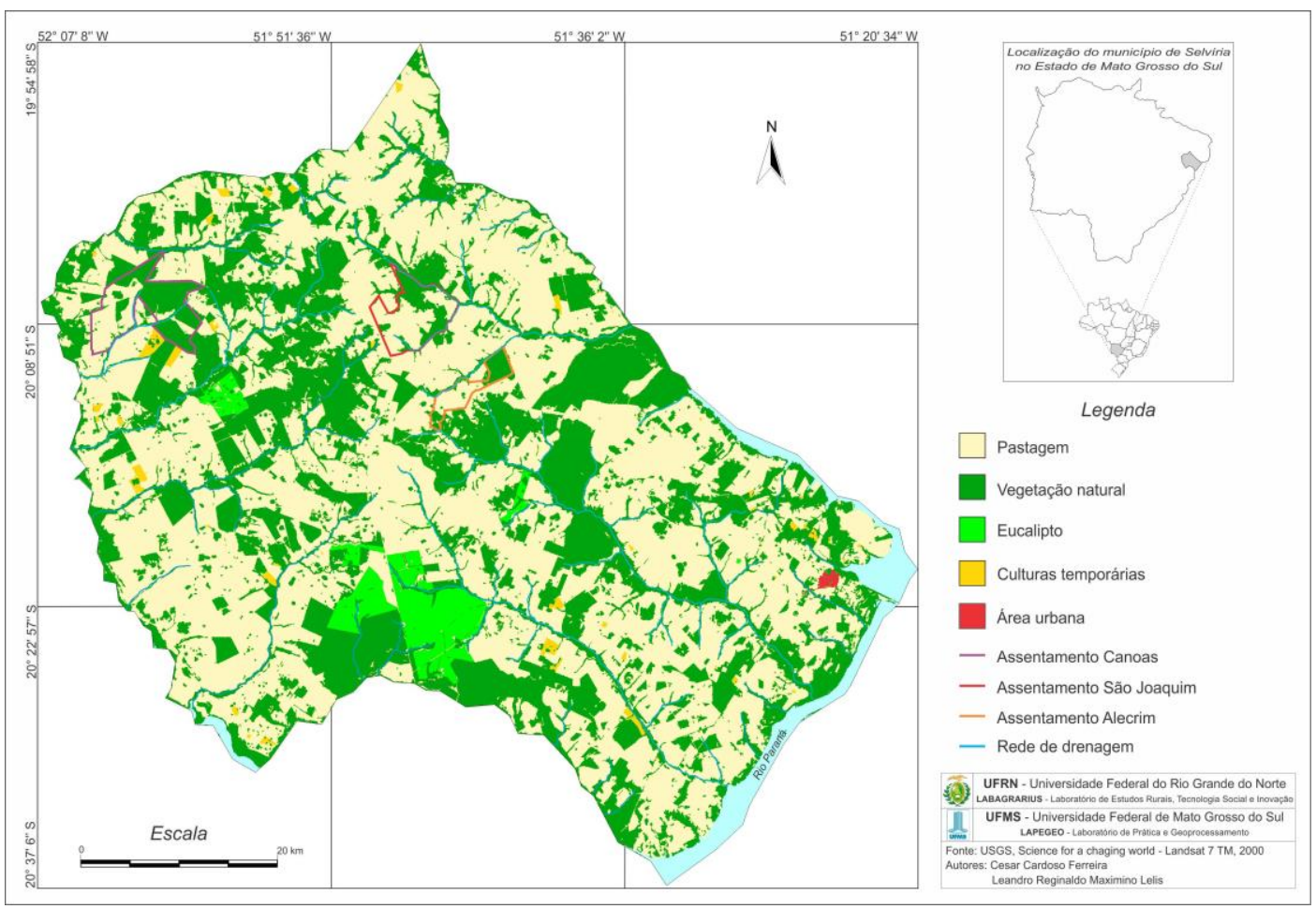

Fonte - USGS - Landsat 7 OLI, 2018.

O mapa 3, que diz respeito ao ano de 2018, evidencia o crescimento significativo da área ocupada pelo monocultivo de eucalipto em Selvíria durante o período analisado. A expansão dos eucaliptais, por conseguinte, ampliou a inserção do município no circuito espacial produtivo de celulose, tendo em vista que suas relações com as companhias produtoras de celulose foram amplificadas.

Mapa 3 - Selvíria: uso e cobertura da terra (2018).
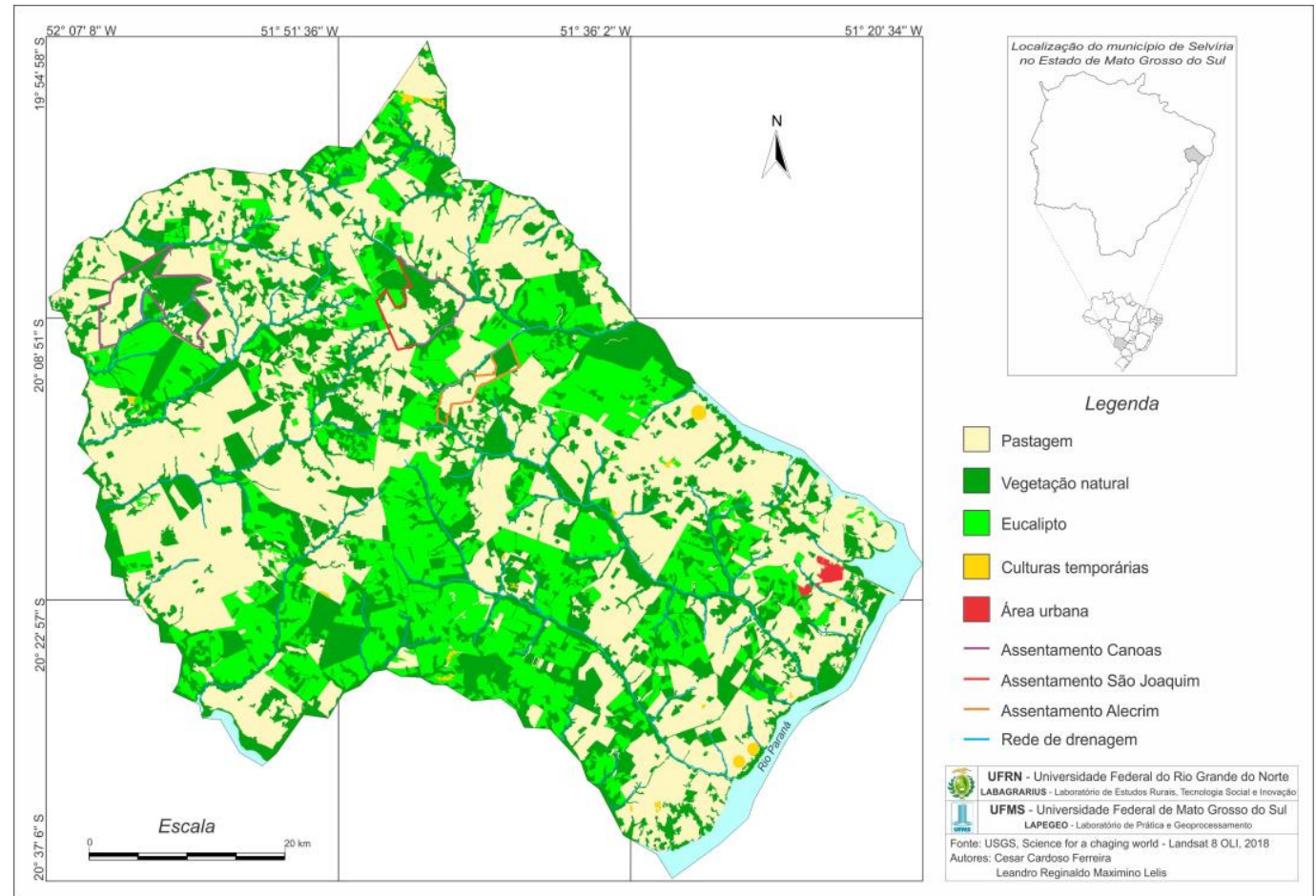

Fonte - USGS - Landsat 8 OLI, 2018. 
A partir dos procedimentos realizados, foi possível averiguar que, entre 2000 e 2018, os eucaliptais apresentaram crescimento de $673,4 \%$, passando de 87,73 quilômetros quadrados $\left(\mathrm{km}^{2}\right)$, em 2000 , para $678,54 \mathrm{~km}^{2}$, em 2018. Em contrapartida, ao passo que os monocultivos de eucaliptos expandiram-se no município, as áreas destinadas à pastagem e às culturas temporárias, além da vegetação natural, apresentaram redução no período analisado (tabela 1).

Tabela 1 - Selvíria: uso e cobertura da terra (2000 e 2018).

\begin{tabular}{lcc}
\hline & $\mathbf{2 0 0 0}$ & $\mathbf{2 0 1 8}$ \\
\hline Classes & $\mathbf{K m}^{\mathbf{2}}$ & $\mathbf{K m}^{\mathbf{2}}$ \\
\hline Pastagem & $1.845,59$ & $1.493,50$ \\
Vegetação natural & $1.207,59$ & 974,89 \\
Eucalipto & 87,73 & 678,54 \\
Culturas temporárias & 21,41 & 9,82 \\
Outros usos & 92,36 & 97,93 \\
\hline Total Fonte - USGS - Landsat 7 e 8 OLI, 2018.
\end{tabular}

Como notado, os mapas 2 e 3 trouxeram, propositalmente, a localização de assentamentos da reforma agrária existentes no município, pois o próximo item será dedicado a analisar os principais desdobramentos ocasionados pela inserção de Selvíria no circuito espacial produtivo de celulose e os assentamentos estão entre os lugares mais afetados.

\section{DESDOBRAMENTOS GERADOS PELA EXPANSÃO DO CIRCUITO ESPACIAL PRODUTIVO DE CELULOSE EM SELVÍRIA}

A expansão do monocultivo de eucalipto em Selvíria tem ampliado sua inserção no circuito espacial produtivo de celulose, pois quanto mais áreas são ocupadas pelo eucalipto, maior é a relação entre o município e as empresas produtoras de celulose e suas prestadoras de serviços.

Durante o trabalho de campo, realizado em agosto de 2018, notou-se que o circuito pesquisado se faz muito presente na dinâmica municipal, ou seja, tanto na cidade como no campo. Na cidade, manifesta-se principalmente por meio da movimentação de trabalhadores em hotéis e restaurantes, da circulação de ônibus que transportam trabalhadores da cidade para os módulos florestais e de caminhões que transportam equipamentos e insumos das empresas para os módulos florestais e toras de eucalipto dos módulos para as fábricas de celulose.

É impossível sair pela cidade de Selvíria e não observar trabalhadores das empresas de celulose e de diversas empresas terceirizadas que prestam serviços nos hotéis e restaurantes da cidade ou esperando ou saindo dos ônibus das empresas prestadoras de serviços que realizam o transporte dos trabalhadores.

Em conversas com donos de hotéis e restaurantes as informações caminharam em uma única direção: o movimento nos hotéis e restaurantes da cidade aumentou consideravelmente após a expansão do eucalipto. A figura 1 evidencia formas da relação entre o circuito espacial produtivo de celulose e a cidade de Selvíria, como a utilização dos serviços de hospedagem de um hotel e o aluguel de uma sala comercial.

Figura 1 - Selvíria: hotel e sala comercial alugada pela Eldorado Brasil.

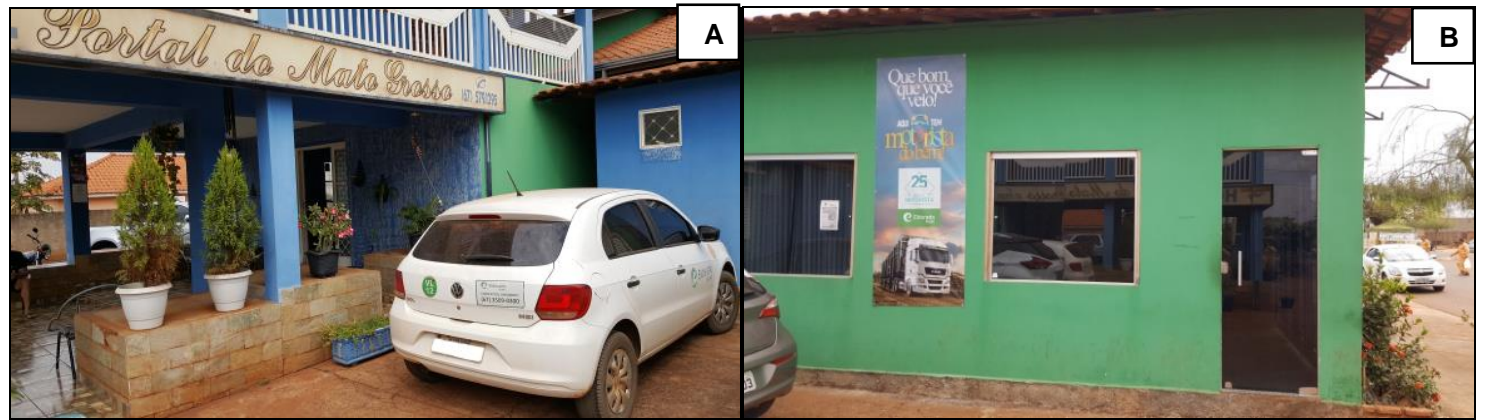

(A) Veículo de propriedade da Eldorado Brasil no estacionamento do Hotel Portal do Mato Grosso. (B) Sala comercial alugada pela Eldorado ao lado do hotel para servir como ponto de apoio para as atividades desenvolvidas pela empresa no município. Fonte - Trabalho de campo, 2018.

$\begin{array}{lllll}\text { Caminhos de Geografia } & \text { Uberlândia } & \text { v. 21, n. } 73 & \text { Mar/2020 } & \text { p. 269-283 Página } 275\end{array}$


Evidente que as empresas não utilizam mão de obra oriunda apenas de outros municípios, pois a mão de obra local também passou a ser absorvida pelas atividades ligadas ao CEPC, especialmente as florestais. Dessa forma, a expansão deste circuito em Selvíria provocou alterações na estrutura ocupacional da mão de obra local.

Os dados da tabela 2 são claros nessa direção. Em 2006, ano do anúncio da instalação da primeira fábrica de celulose, as principais atividades geradoras de vínculos empregatícios eram a criação de bovinos (371) e a administração pública em geral (358). Em 2015, essa situação foi alterada, pois a administração pública em geral passou a ocupar o topo em relação aos vínculos ativos, com 524 vínculos ativos, seguida de perto pela produção florestal - florestas plantadas, com 517 . Enquanto isso, a criação bovina caiu para o terceiro lugar, apresentando 334 vínculos ativos, apresentando pequeno decréscimo se comparado com o número de vínculos existentes em 2006.

Tabela 2 - Selvíria: principais atividades em número de vínculos ativos (2006 e 2015).

\begin{tabular}{|c|c|c|c|}
\hline \multicolumn{2}{|l|}{2006} & \multicolumn{2}{|l|}{2015} \\
\hline Atividade & № & Atividade & № \\
\hline Criação de bovinos & 371 & Administração pública em geral & 524 \\
\hline Administração pública em geral & 358 & Produção florestal - florestas plantadas & 517 \\
\hline Confecção de roupas íntimas & 49 & Criação de bovines & 334 \\
\hline $\begin{array}{l}\text { Fabricação de calçados de material } \\
\text { sintético }\end{array}$ & 32 & $\begin{array}{l}\text { Fabricação de calçados de materiais não } \\
\text { especificados anteriormente }\end{array}$ & 103 \\
\hline $\begin{array}{l}\text { Fabricação de produtos cerâmicos não- } \\
\text { refratários para uso estrutural na } \\
\text { construção }\end{array}$ & 28 & Confecção de roupas profissionais & 94 \\
\hline $\begin{array}{l}\text { Recuperação de materiais não } \\
\text { especificados anteriormente }\end{array}$ & 27 & $\begin{array}{l}\text { Comércio varejista de combustíveis para } \\
\text { veículos automotores }\end{array}$ & 33 \\
\hline
\end{tabular}
Fonte - MTE/RAIS, 2017.

As alterações na ocupação da mão de obra provocaram reflexos nas relações de trabalho no Leste sul-mato-grossense. Segundo o presidente do Sindicato do Trabalhador Florestal (SINTRAF), localizado em Três Lagoas, se em um primeiro momento trabalhar nas atividades florestais relacionadas ao circuito especial produtivo de celulose era visto como uma ótima oportunidade de trabalho na região, com o passar do tempo essa situação foi alterada. De acordo com o entrevistado, tal inversão ocorreu em decorrência das condições de trabalho insatisfatórias, como a falta de locais adequados para a alimentação, descanso e realização das necessidades fisiológicas. Além disso, questões relacionadas ao salário, como, por exemplo, o não pagamento integral das horas in itinere, e à alta rotatividade dos trabalhadores também tem contribuído para o desprestígio do trabalho florestal nos últimos anos.

Conforme o presidente do SINTRAF, em função do não oferecimento de uma infraestrutura adequada, os trabalhadores florestais se alimentam e realizam suas necessidades fisiológicas ao lado das máquinas, ficando sujeitos ao ataque de animais peçonhentos, como já ocorreu com alguns trabalhadores. A falta de infraestrutura aliada à cobrança pela produtividade também faz com que os trabalhadores não descansem após a alimentação. Segundo o entrevistado, estes preferem voltar às suas atividades, a fim de atingir suas metas, a ficarem "descansando" em lugares inadequados.

De acordo o Presidente do SINTRAF, nos últimos anos, as empresas tentaram se enquadrar buscando oferecer melhores condições de trabalho após denúncia realizada junto ao Ministério Público do Trabalho (MPT). Entretanto, as adequações foram realizadas de maneira equivocada. As áreas de convivência destinadas à alimentação nos módulos florestais, por exemplo, normalmente não acomodam todos os trabalhadores adequadamente. Por isso, muitos trabalhadores permanecem realizando suas refeições em condições impróprias.

Os banheiros químicos inseridos nos hortos florestais, por seu lado, ficam fixos, não acompanhando as máquinas que se movem bastante durante um turno de trabalho. Tal contexto faz com que os trabalhadores fiquem distantes dos banheiros e permaneçam realizando suas necessidades em lugares inadequados, pois o deslocamento até o banheiro resulta na redução da produtividade em razão do tempo de deslocamento.

\begin{tabular}{llllll}
\hline Caminhos de Geografia & Uberlândia & v. 21, n. 73 & Mar/2020 & p. 269-283 Página 276
\end{tabular}


No que diz respeito às horas in itinere (termo que se refere ao tempo que o trabalhador leva para se deslocar até o local de trabalho), o presidente do SINTRAF relatou que os trabalhadores deslocam-se por horas até chegar ao horto florestal e, posteriormente, para retornar às suas residências, pois as distâncias a serem percorridas costumam ser grandes, podendo atingir mais de 100 quilômetros. Apesar da luta antiga dos trabalhadores para receber os valores referentes às horas in itinere integralmente, as empresas atuam no sentidode reduzir os ganhos referentes às horas em questão. Nessa disputa, as empresas levam vantagem, tendo em vista que os trabalhadores nunca conseguem receber as horas referentes ao deslocamento integralmente.

A alta rotatividade dos trabalhadores, por sua vez, está ligada à formação de mão de obra excedente na região, que possibilitou às empresas a substituição dos trabalhadores que atigem níveis salariais mais altos por trabalhadores recém qualificados, devido ao interesse em reduzir custos. Segundo o presidente do SINTRAF, essa característica é relativamente recente, pois no início da atuação das empresas fabricantes de celulose no Leste de Mato Grosso do Sul a mão de obra era pouco qualificada, tornando as companhias mais dependentes dos trabalhadores qualificados. Após alguns anos, com a ampliação significativa do número de pessoas formadas e qualificadas para atuar nas atividades ligadas ao CEPC, principalmente em razão da atuação das empresas em parceria com o Serviço Nacional de Aprendizagem Industrial (SENAI), essa conjutura foi alterada e as companhias tornaram-se menos dependentes da mão de obra em decorrência da grande quantidade de trabalhadores qualificados disponíveis no mercado.

Importante destacar que, apesar das alterações ocorridas no mercado de trabalho, Selvíria não atraiu grande número de migrantes após a expansão do circuito espacial produtivo de celulose, ao contrário do que foi verificado em Três Lagoas. Entre os anos de 2000 e 2018, segundo dados do Instituto Brasileiro de Geografia e Estatística (IBGE), Selvíria registrou crescimento populacional de apenas $7,0 \%$, passando de 6.085 habitantes, em 2000, para 6.515 moradores, em 2018. Três Lagoas, por seu lado, apresentou crescimento de 51,1\%, passando de 79.059 habitantes, em 2000, para 119.465 habitantes, em 2018 (tabela 3).

Tabela 3 - Três Lagoas e Selvíria: população total.

\begin{tabular}{lccc}
\hline & $\mathbf{2 0 0 0}$ & $\mathbf{2 0 1 0}$ & $\mathbf{2 0 1 8}$ \\
Selvíria & 6.085 & 6.287 & $6.515^{\star}$ \\
Três Lagoas & 79.059 & 101.722 & $119.465^{\star}$ \\
\hline \multicolumn{4}{c}{ *Estimativa elaborada pelo IBGE. } \\
& Fonte - IBGE, 2000-2018).
\end{tabular}

Os dados da tabela 3 evidenciaram que Três Lagoas, por ser polo regional e sede das unidades industriais produtoras de celulose, apresentou mudanças demográficas consideráveis, pois concentrou a maior parte dos migrantes que foram para o Leste sul-mato-grossense após o anúncio da instalação da primeira fábrica de celulose, em 2006. Para Perpetua (2012, p. 190):

\begin{abstract}
Pode-se afirmar que a partir do ano de 2006, Três Lagoas entrou definitivamente na rota dos fluxos migratórios internos brasileiros, recebendo um significativo contigente de trabalhadores, vindos de diversos pontos do território nacional para ocupar diferentes lugares na estrutura hierárquica de controle do capital.
\end{abstract}

A redução das pastagens (mapa 3; tabela 1) e do número de vínculos ativos na criação de bovinos (tabela 2), evidenciam outra consequência da expansão dos monocultivos florestais em Selvíria: a redução do rebanho bovino; uma das principais atividades econômicas do município até então. Os dados da tabela 4 evidenciam que, entre 2000 e 2017, o efetivo bovino municipal registrou redução de 29,9\%, passando de 265.010 cabeças, em 2000, para 185.717 cabeças, em 2017.

Tabela 4 - Selvíria: efetivo bovino (2000-2017).

\begin{tabular}{cc}
\hline Anos & № de cabeças \\
\hline 2000 & 265.010 \\
2005 & 276.757 \\
2010 & 219.104 \\
2015 & 192.622 \\
2017 & 185.717 \\
\hline
\end{tabular}

Fonte - IBGE - Pesquisa Pecuária Municipal, 2000-2017.

$\begin{array}{lllll}\text { Caminhos de Geografia } & \text { Uberlândia } & \text { v. 21, n. } 73 & \text { Mar/2020 } & \text { p. 269-283 Página } 277\end{array}$


Continuando no campo, averiguou-se que os assentamentos da reforma agrária concentram grande parte dos sujeitos sociais afetados pela expansão do monocultivo de eucalipto para a produção de celulose. Isso porque as empresas, em decorrência de seus projetos sociais de compensação, atuam diretamente junto aos assentados, doando insumos, equipamentos e materiais, fornecendo assistência técnica, realizando obras, cursos e projetos etc. No Assentamento São Joaquim, por exemplo, a Eldorado Brasil construiu uma escola (figura 3).

Figura 3 - Assentamento São Joaquim: escola construída com recursos da Eldorado Brasil.

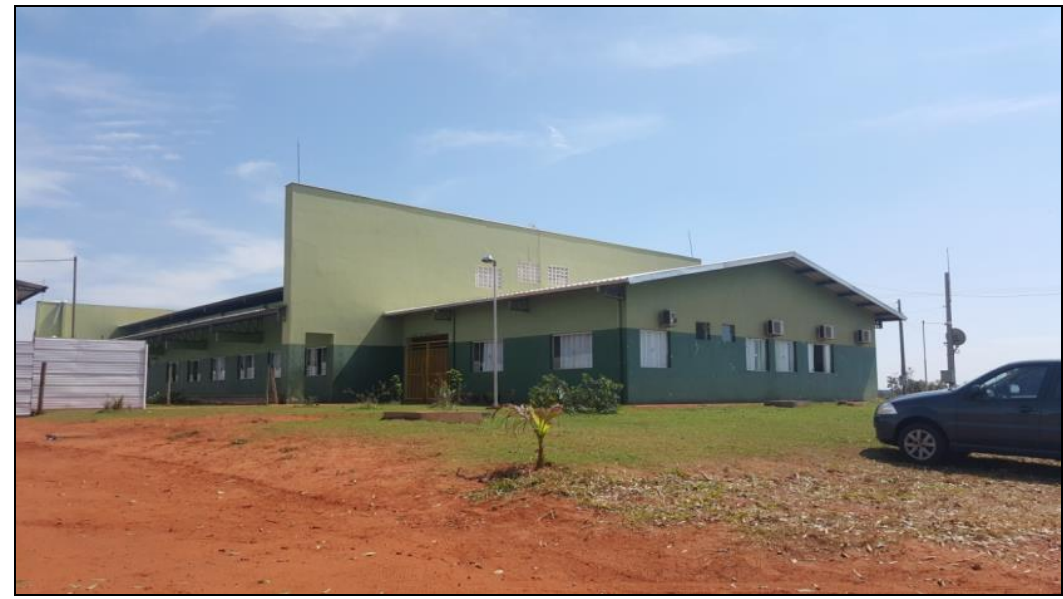

Fonte - Trabalho de campo, 2018.

Nas entrevistas realizadas, notou-se consenso em relação aos benefícios gerados pelas ações desenvolvidas pelas companhias. Segundo os assentados pesquisados, a situação era pior antes da atuação das companhias em virtude do descaso por parte do Estado, nas instâncias federal, estadual e municipal. Assim, as ações promovidas pelas empresas junto aos assentados contribuem para o desenvolvimento das atividades no lote, contribuindo, por consequência, para a reprodução familiar no assentamento.

Se por um lado a atuação das empresas de celulose contribui para o desenvolvimento das atividades e para a reprodução familiar, proporcionando relativa emancipação aos assentados, por outro revela uma situação de tutela, pois os assentados tornam-se dependentes das ações realizadas pelas empresas, conforme pode ser notado na fala da presidente da Associação dos Produtores Rurais do Assentamento Alecrim:

A gente tem dependência muito grande deles. [...] Eu nunca tive o sonho de, por exemplo, colocar piso na minha casa, e eu consegui através que eles ajudaram a gente com o adubo, com a pastagem, com a semente. [...] Com tudo que eles ajudaram, a gente consegue investir em alguma coisa de dentro de casa. Por exemplo, você deixa de comprar um ano o adubo que você manteria o lote e você compra uma, duas vacas de leite. (Entrevista realizada em agosto de 2018).

Os benefícios gerados pela atuação das empresas junto aos assentamentos, todavia, contrastam com vários impactos gerados pela expansão do monocultivo de eucalipto no campo, afetando os lotes localizados próximos aos eucaliptais.

A partir das entrevistas, inferiu-se que os principais impactos gerados pelas atividades ligadas ao CEPC aos assentamentos são: a deterioração das estradas rurais e a poeira gerada pelo tráfego de veículos, a invasão de pragas advindas dos eucaliptais, a contaminação das lavouras por agrotóxicos pulverizados nos eucaliptos e a redução dos cursos d'água localizados nas proximidades dos assentamentos.

Estes impactos são ocasionados pela proximidade entre os assentamentos da reforma agrária e os eucaliptais, como pôde ser averiguado no mapa 3. A figura 4, por meio de imagens dos assentamentos São Joaquim e Alecrim, também demonstra essa relação de proximidade.

$\begin{array}{lllll}\text { Caminhos de Geografia } & \text { Uberlândia } & \text { v. 21, n. } 73 & \text { Mar/2020 } & \text { p. 269-283 Página } 278\end{array}$


Figura 4 - Assentamentos São Joaquim e Alecrim: proximidade em relação aos eucaliptais.

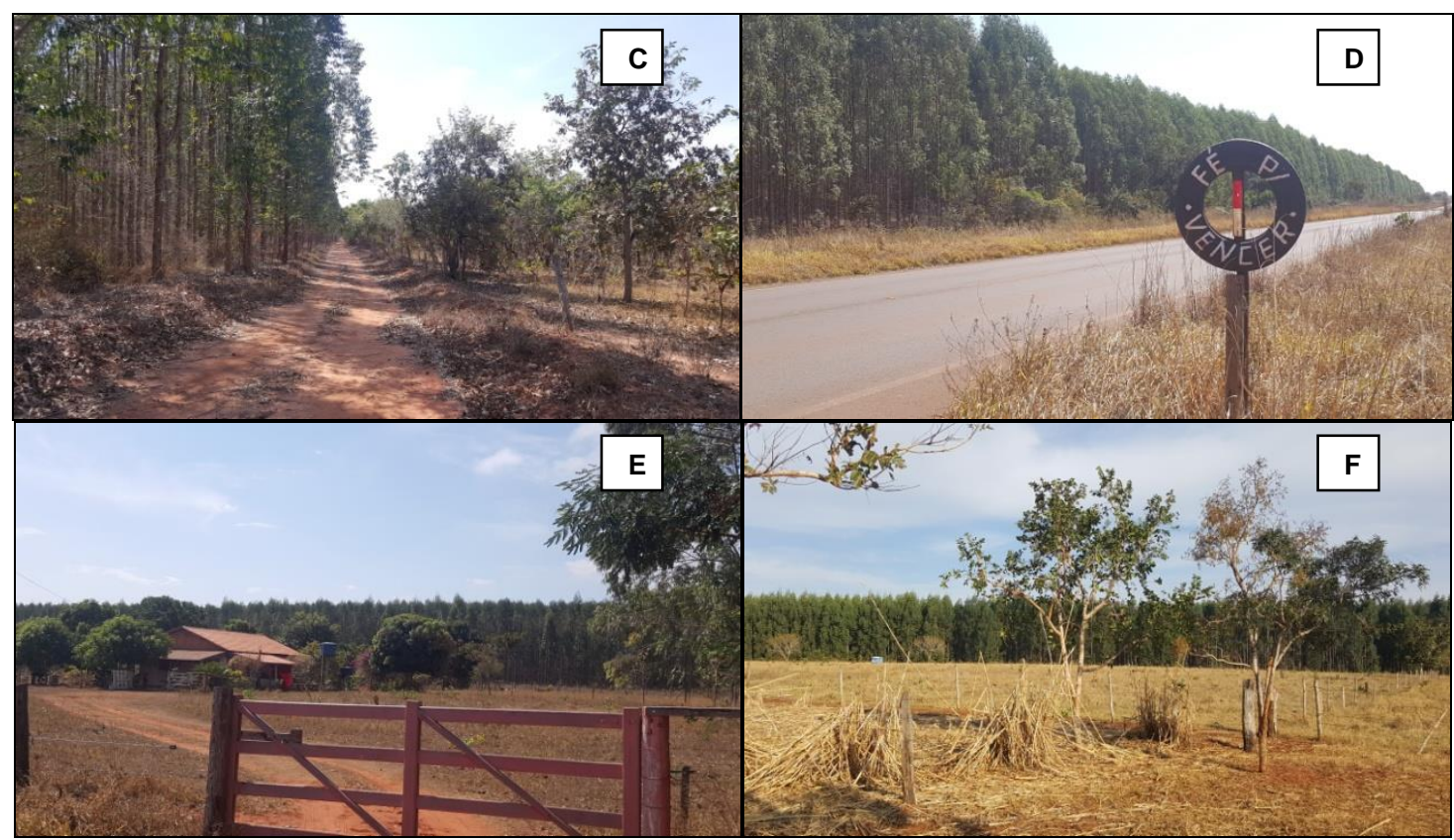

(C) Estreita estrada rural que separa um dos lotes do São Joaquim do monocultivo de eucalipto. (D) Eucaliptal existente em frente a uma das entradas do assentamento, do outro lado da rodovia MS-112. (E) Moradia de um dos lotes do assentamento e, ao fundo, os eucaliptos. (F) Eucaliptos que cercam lote do Assentamento Alecrim. Fonte - Trabalho de campo, 2018.

A proximidade dos assentamentos em relação aos eucaliptais faz com que os caminhões e ônibus das empresas integrantes do CEPC utilizem as estradas rurais próximas, inclusive as localizadas no interior dos assentamentos, gerando transtornos aos assentados, sobretudo nos assentamentos Alecrim e Canoas, pois as estradas que passam por esses assentamentos não são pavimentadas.

Segundo os moradores, as empresas realizam a manutenção das estradas durante o período de maior tráfego, não para beneficiá-los, mas a fim de oferecer as melhores condições possíveis para a circulação de sua frota, objetivando reduzir os custos com a sua manutenção. No entanto, após a realização das atividades nos módulos florestais, as estradas são deixadas em péssimas condições.

Ainda conforme os moradores, a poeira é outro problema gerado pela circulação intensa dos veículos pertencentes às empresas ligadas ao circuito espacial produtivo de celulose, pois estes trafegam nas estradas rurais existentes no interior dos assentamentos. $O$ trecho da entrevista concedida por um morador do Assentamento Alecrim é claro nesse sentido:

\begin{abstract}
Esses dias tive que parar um motorista da Eldorado, com a maior educação, e falar que ele tava passando muito rápido. Pedi pra ele passar mais devagar. Falei que tava sujando dentro da minha casa, as roupas no varal. Ele pediu desculpa. O duro é que não é só um caminhoneiro, são vários [...]. Esses dias um morador ficou muito bravo com a poeira e falou que iria colocar uma barreira pra não deixar os caminhões passar, que só iria deixar passar se jogassem água na frente da casa dele. Aí eles foram e jogaram água, mas só na frente da casa dele, na minha não fizeram isso. (Entrevista realizada em agosto de 2018).
\end{abstract}

Segundo o Gestor de Produção do Assentamento Canoas, existem diversos problemas relacionados ao tráfego de caminhões e ônibus relacionados ao circuito espacial produtivo de celulose. Nesse sentido, é comum que os moradores da região, incluindo produtores que não morem nos assentamentos, coloquem obstáculos para dificultar a circulação dos veículos, principalmente para mantê-los distantes das cercas de suas propriedades, constantemente atingidas e danificadas por caminhões que transportam toras de eucalipto.

Lá na região é comum deixar algum obstáculo, colocar madeiras perto das cercas pra dificultar a passagem, pra ver se eles afastam um pouco da cerca, porque os caminhões passam muito perto e quebram as cercas. [...] Teve um caso no ano passado que derrubaram uma rede de luz e o motorista fugiu. Depois até arrumaram, mas ficou quatro dias sem luz lá. (Gestor de Produção do Assentamento Canoas. Entrevista realizada em agosto de 2018).

$\begin{array}{lllll}\text { Caminhos de Geografia } & \text { Uberlândia } & \text { v. 21, n. 73 } & \text { Mar/2020 } & \text { p. 269-283 Página } 279\end{array}$


Outro problema gerado pela proximidade entre os assentamentos e o monocultivo de eucalipto é o aparecimento de pragas. De acordo com moradores dos assentamentos, em determinadas épocas do ano, principalmente após a aplicação de agrotóxicos nos eucaliptos, é muito comum o aparecimento de um pequeno besouro amarelo, que ataca, mormente, os pés de goiaba. Os depoimentos a seguir elucidam tal questão:

O que prejudica é um bichinho que sai do eucalipto, um besourinho amarelo fedido. Ele prejudica até dentro de casa, entra e deixa a casa toda fedida. Eles prejudicam a goiaba também. Quem tem plantio de goiaba perde tudo. Ele come tudo, come até a folha (Morador do Assentamento Alecrim. Entrevista realizada em agosto de 2018).

Tem uma época que eles passam veneno no eucalipto e os bichinhos de lá vem tudo pra cá. Aqui dá uns besourinhos amarelos que, rapaz, os pés de goiaba que têm aqui eles comem tudo. (Morador do Assentamento São Joaquim. Entrevista realizada em agosto de 2018).

A contaminação das lavouras pelos agrotóxicos configura-se como outro desdobramento da proximidade em relação aos eucaliptais. De acordo com os assentados pesquisados, os agrotóxicos aplicados nos eucaliptos, muitas vezes, atingem suas lavouras, ocasionado a perda de parte da produção. Além disso, os assentados que produzem orgânicos próximos ao monocultivo de eucalipto também são prejudicados, pois suas produções podem ser contaminadas pelos agrotóxicos, como pode ser notado a seguir:

Eu trabalho com orgânico, moro em frente do eucalipto. Uma coisa que eu acho que prejudicou, na minha parte, é o herbicida que eles passam. O herbicida que eles passam seca de um jeito que não fica nada na terra. Seca tudo mesmo! [...] E outra, em frente de casa, fica aquele cheirão, sabe?! [...]. Eu até conversei com a menina da Eldorado e falei pra ela se não era possível, pelo menos nessa frente aqui, roçar em vez de passar herbicida. Falei da situação da minha horta, que prejudica ela. (Morador do Assentamento Alecrim. Entrevista realizada em agosto de 2018).

Vale salientar que a aplicação de agrotóxicos também pode atingir as pessoas, tanto as que trabalham em sua aplicação como as que residem nas proximidades dos eucaliptais. Cercados pelo monocultivo de eucalipto, os assentados frequentemente inalam agrotóxicos transportados pelo ar, como pôde ser notado no depoimento anterior, no qual o morador reclamou do odor produzido pela aplicação de herbicidas.

Conforme Bombardi (2011, p. 20), o uso de agrotóxicos no Brasil tem provocado consequências maléficas à sociedade, pois "os camponeses, trabalhadores rurais, os familiares destes trabalhadores e moradores de áreas próximas aos cultivos contaminados com agrotóxicos estão sendo intoxicados cotidianamente de forma direta". Nesse sentido, para Rigotto e Augusto (2007, p. S482):

Uma das conseqüências da modernização tecnológica da agricultura no mundo e das iniqüidades produzidas pela divisão internacional do trabalho é evidenciada pelos 3 milhões de envenenamentos humanos anuais, com aproximadamente 220 mil mortes, das quais $70 \%$ ocorrem nos países em desenvolvimento.

A expansão do monocultivo de eucalipto também proporciona outro desdobramento percebido pelos assentados: a redução dos cursos d'água. Segundo os assentados pesquisados, o nível dos cursos d'água reduziu significativamente nos últimos 10,15 anos, coincidindo com o período de expansão do eucalipto no município. A relação entre a expansão do eucalipto e a redução dos cursos d'água pode ser observada nos depoimentos abaixo:

Ali mesmo onde eu trabalhava plantou eucalipto. Antes tinha dois açudes. Um que era menorzinho tem bem pouquinha água, mas isso tem um tempo já. Hoje acho que nem tem mais água. [...] O eucalipto puxa muita água. (Morador do Assentamento São Joaquim. Entrevista realizada em agosto de 2018).

Eles [Eldorado Brasil] tinham dentro de uma fazenda cinco represas, hoje só tem duas. As outras secaram. Isso dentro do horto deles. [...] Antigamente, quando a gente ia pra Três Lagoas, depois do São Joaquim, a gente via passagens de água a cada 10, 15 quilômetros. Cada baixada tinha uma. Hoje a gente passa lá e só vê a passagem, a água não tem mais. [...] Você pode até ir lá olhar, ainda existem as placas dos córregos, mas não tem mais água. (Moradora do Assentamento Canoas. Entrevista realizada em agosto de 2018).

$\begin{array}{lllll}\text { Caminhos de Geografia } & \text { Uberlândia } & \text { v. 21, n. } 73 & \text { Mar/2020 } & \text { p. 269-283 Página } 280\end{array}$


A parte final do trecho da entrevista anterior, concedida por uma moradora do Assentamento Canoas, que revelou a redução dos cursos d'água entre no trajeto entre o assentamento e Três Lagoas, principalmente após o Assentamento São Joaquim, foi verificada empiricamente. De fato, não existem mais cursos d'água visíveis. É possível apenas observar as placas indicando os córregos e a grande quantidade de eucalipto nas proximidades, como pode ser visto na figura 5 , que apresenta imagens dos córregos Cabrito e Carro Queimado.

Figura 5 - Selvíria: situação atual de alguns cursos d’água cercados por eucaliptos.

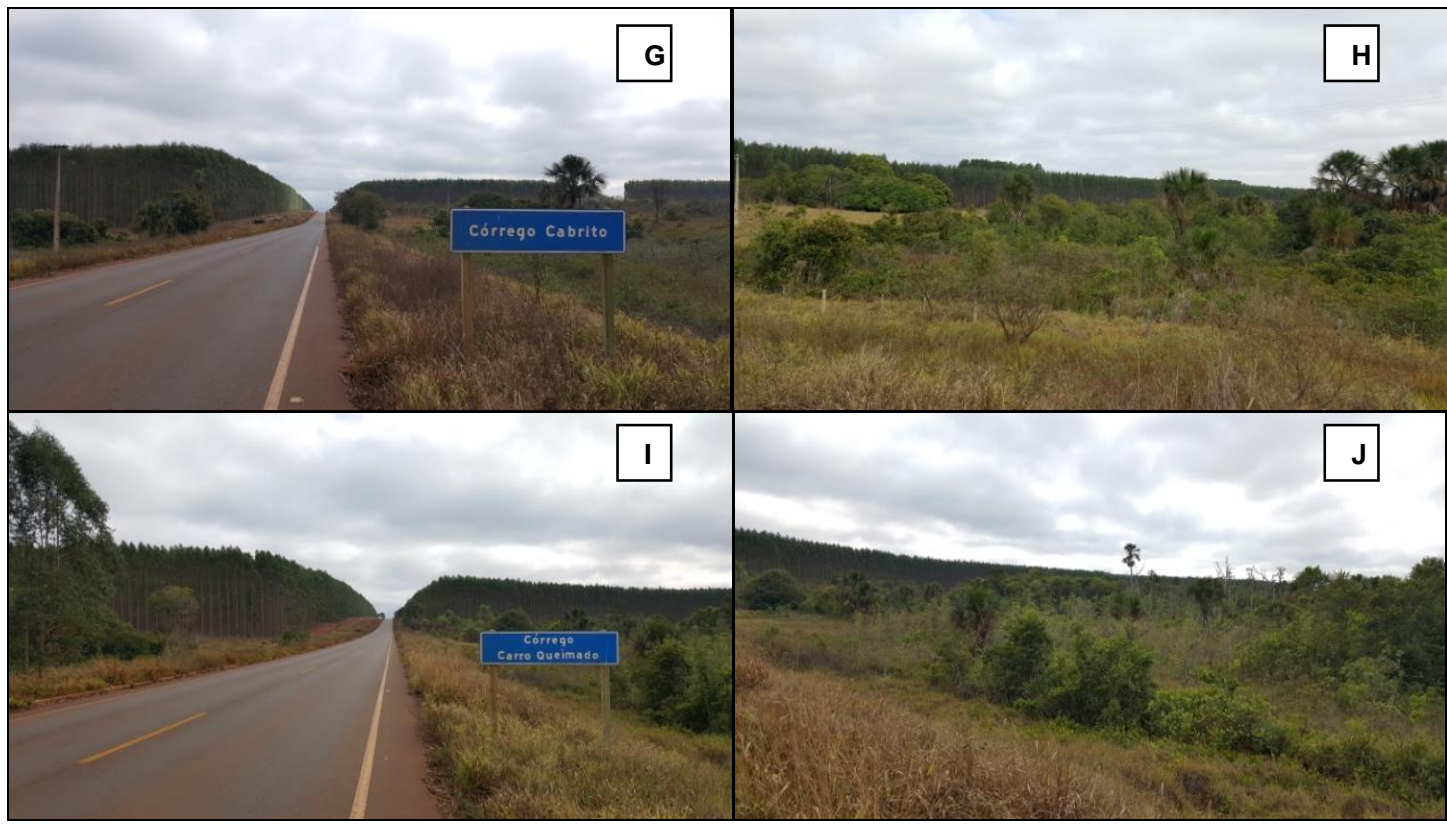

(G) Placa indicando a localização do córrego Cabrito e, ao fundo, a grande quantidade de eucalipto existente nas proximidades. (H) Área por onde deveria passar o córrego Cabrito, mas ocupada apenas por vegetação. (I) Monocultivo de eucalipto que cerca o córrego Carro Queimado. (J) Área onde era possível observar o curso d'água do córrego Carro Queimado. Fonte - Trabalho de campo, 2018.

Enquanto os moradores do campo observam a redução dos cursos d'água, pesquisadores defensores das atividades florestais afirmam que o eucalipto consome a mesma quantidade de água que qualquer outra árvore. Todavia, mesmo que o consumo de água seja equivalente, é importante considerar duas questões: os poucos estudos existentes sobre a relação entre a água e o monocultivo de eucalipto no Cerrado; e, a grande área ocupada pelo eucalipto em Mato Grosso do Sul (PERPETUA, 2016).

Em 2016, por exemplo, os eucaliptais ocupavam cerca de 900 mil de hectares em Mato Grosso do Sul, concentrados, sobretudo, na região Leste. Somente a Fibria e a Eldorado possuíam juntas mais de 500 mil hectares ocupados pelo eucalipto. Assim, a grande quantidade de árvores exóticas plantadas possivelmente influencia no balanço hídrico regional.

Além do consumo de água pelo eucalipto, também é importante considerar que as empresas captam água nos cursos existentes no interior de suas fazendas próprias ou arrendadas. Um dos moradores do Assentamento Alecrim informou que observou, diversas vezes, caminhões-pipa retirando água dos açudes localizados nas fazendas, situação que também pode ser um dos motivos da redução dos cursos d'água na região.

\section{CONSIDERAÇÕES FINAIS}

As imagens de satélite evidenciam o crescimento dos eucaliptais em Selvíria para o abastecimento das fábricas de celulose localizadas em Três Lagoas. Esse crescimento tem causado a ampliação da inserção do município pesquisado no circuito espacial produtivo de celulose, gerando desdobramentos como a ampliação do movimento dos hotéis e restaurantes e da circulação de ônibus e caminhões das empresas ligados ao circuito espacial produtivo de celulose, a alteração na

$\begin{array}{llllll}\text { Caminhos de Geografia } & \text { Uberlândia } & \text { v. 21, n. 73 } & \text { Mar/2020 } & \text { p. 269-283 Página } 281\end{array}$


estrutura ocupacional da mão de obra local e a redução do rebanho bovino. Entretanto, os maiores desdobramentos são sentidos nos assentamentos da reforma agrária.

Em virtude de estarem localizados na área de influência das atividades das companhias fabricantes de celulose, os assentamentos recebem projetos, doações, dentre outras ações e atividades que contribuem para o desenvolvimento das atividades dos assentados no lote, viabilizando a reprodução familiar. Tal situação contribui para a relativa emancipação dos assentados, no entanto também amplia sua dependência em relação às empresas, evidenciando uma relação de tutela.

Ademais, também se averiguou que as atividades ligadas ao CEPC geram diversos impactos no campo que afetam os assentados, como a deterioração das estradas rurais, a poeira ocasionada pelo tráfego intenso de veículos, sobretudo caminhões e ônibus, a invasão de pragas, a contaminação das lavouras por agrotóxicos aplicados nos eucaliptais e a redução dos cursos d'água.

Por fim, conclui-se que mais do que a produção de celulose e de sua matéria-prima, o eucalipto, o circuito espacial produtivo de celulose causa desdobramentos que vão além da esfera econômica, atingindo também as esferas social e ambiental em Mato Grosso do Sul, sobretudo em sua porção Leste, onde estão localizadas as duas fábricas de celulose e a maior parte dos eucaliptais existentes no estado.

\section{AGRADECIMENTOS}

O presente trabalho foi realizado com apoio da Coordenação de Aperfeiçoamento de Pessoal de Nível Superior - Brasil (CAPES).

\section{REFERÊNCIAS}

ALMEIDA, R. A. A territorialização do agronegócio do eucalipto na região leste de Mato Grosso do Sul e o cerco à reforma agrária. In: ENCONTRO NACIONAL DE GEÓGRAFOS, XVI, 2010, Porto Alegre. Anais... Porto Alegre: Associação dos Geógrafos Brasileiros, 2010.

BOMBARDI, L. M. Intoxicação e morte por agrotóxicos no Brasil: a nova versão do capitalismo oligopolizado. Boletim DATALUTA, 2011, p. 1-21. Disponível em: $<$ http://docs.fct.unesp.br/grupos/nera/artigodomes/9artigodomes 2011.pdf>. Acesso em: 22 abr. 2019. https://doi.org/10.1590/S1982-45132010000300004

CASTILLO, R.; FREDERICO, S. Espaço geográfico, produção e movimento: uma reflexão sobre o conceito de circuito espacial produtivo. Sociedade \& Natureza, Uberlândia, n. 22, p. 461-474, 2010. Disponível em: <http://www.seer.ufu.br/index.php/sociedadenatureza/article/view/11336>. Acesso em: 15 jun. 2016.

IBGE. Instituto Brasileiro de Geografia e Estatística. Pesquisa Pecuária Municipal (2000 a 2017). Disponível em: <http://www.sidra.ibge.gov.br>. Acesso em: 15 abr. de 2019.

IBGE. Instituto Brasileiro de Geografia e Estatística. Cidades. Disponível em: $<$ https://cidades.ibge.gov.br/brasil/ms/selviria/panorama>. Acesso em: 10 abr. 2019.

KUDLAVICZ, M. Dinâmica agrária e a territorialização do complexo celulose/papel na Microrregião de Três Lagoas/MS. 2011. 176 f. 2011. Dissertação (Mestrado em Geografia) Universidade Federal de Mato Grosso do Sul, Três Lagoas, 2011.

MARX, K. Grundrisse. Tradução: Mario Duayer e Nélio Schneider. São Paulo: Boitempo, 2011.

MORAES, A. C. R. Os Circuitos espaciais da produção e os círculos de cooperação no espaço, 1985.

PERPETUA, G. M. A mobilidade espacial do capital e da força de trabalho na produção de celulose e papel: um estudo a partir de Três Lagoas (MS). 2012. 251 f. Dissertação (Mestrado em Geografia) - Faculdade de Ciências Humanas, Universidade Federal da Grande Dourados, Dourados, 2012.

Pilhagem territorial, precarização do trabalho e degradação do sujeito que trabalha: a territorialização do capital arbóreo-celulósico no Brasil contemporâneo. 2016. 370 f. Tese (Doutorado

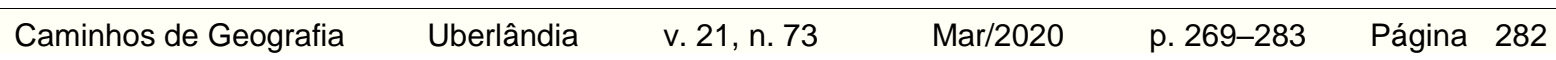


em Geografia) - Faculdade de Ciências e Tecnologia, Universidade Estadual Paulista, Presidente Prudente, 2016.

RIGOTTO R. M.; AUGUSTO L. G. S. Saúde e ambiente no Brasil: desenvolvimento, território e iniqüidade social. Cadernos de Saúde Pública, Rio de Janeiro, 23, S475-S501, 2007. Disponível em: $<$ https://www.nescon.medicina.ufmg.br/biblioteca/imagem/0504.pdf>. Acesso em: 22 abr. 2019. https://doi.org/10.1590/S0102-311X2007001600002

SANTOS, M. Metamorfoses do espaço habitado. 5 ed. São Paulo: Hucitec, 1997.

; SILVEIRA, M. L. O Brasil: território e sociedade no início do século XXI. 18 ed. Rio de Janeiro: Record, 2014.

Recebido em: 14/06/2019

Aceito para publicação em: 23/10/2019 